\title{
Screening and Evaluation of Antibacterial Metabolites from Entomopathogenic Fungi
}

\author{
Tae-Young Shin, Seung-Hyun Ko, Won-Woo Lee, Sung-Min Bae, Jae-Bang Choi, and Soo-Dong Woo* \\ Department of Agricultural Biology, College of Agriculture, Life \& Environment Science, Chungbuk National University, Cheongju 361-763, Republic of Korea
}

\section{Abstract}

Entomopathogenic fungal species have been investigated for their potential use as biological control agents owing to their natural role as insect pathogens. These fungi produce a wide range of secondary metabolites with high therapeutic values, such as antibiotics and cytotoxic substances. To evaluate the antibacterial activity of entomopathogenic fungi, 10 isolates from Korean soil were selected and tested for their activity against Escherichia coli by using fungal culture filtrates. Antibacterial activity was assessed using a two-step process: (1) a screening assay for the selection of fungal isolates and (2) a quantitative assay to evaluate the activity of select fungi. Although 4 fungal isolates were selected through the screening assay, only 3 fungal isolates, from Beauveria bassiana and Metarhizium anisopliae, showed high antibacterial activity according to the quantitative assay. The antibacterial activity of selected fungal culture filtrates was stable when exposed to heat and proteolytic enzyme treatments, which indicated that the antibacterial compound is not a protein. These entomopathogenic fungal metabolites might be useful as a source for bacterial control and in the pharmaceutical industry.

Received : 10 May 2013

Accepted : 17 May 2013

Keywords:

Entomopathogenic fungi,

Fungal metabolites,

Antibacterial activity,

Escherichia coli

\section{Introduction}

Entomopathogenic fungi are natural pathogens of insects and contribute to the regulation of host insect populations in the natural environment. Their mode of action against insects involves the attachment of conidia to the insect cuticle followed by germination, cuticle penetration, and internal dissemination throughout the insect (Vega et al., 2012). During this process, secreted enzymes, protein toxins, and secondary metabolites can be used by fungi to overcome the host immune system, modify host behavior, and defend host resources against competing pathogens and saprophytes (Isaka et al., 2005; Molnár et al., 2010).

Recently, secondary metabolites isolated from entomopathogenic fungi have been reported as potential bioactive substances (Isaka et al., 2005; Molnár et al., 2010). The antimicrobial effect of entomopathogenic fungi [e.g., Beauveria bassiana (Bals.) Vuill., Metarhizium anisopliae (Metchn.) Sorokin, Isaria spp., and Lecanicillium spp.] in the suppression of plant disease caused by plant pathogens such as Alternaria solani, Botrytis cinerea, Fusarium oxysporum, Rizoctonia solani,

\section{*Corresponding Author:}

Soo-Dong Woo

Department of Agricultural Biology, College of Agriculture, Life \& Environment Science, Chungbuk National University, Cheongju 361-763, Republic of Korea.

Tel: +82-43-261-2553 / FAX: +82-43-271-4414

E-mail: sdwoo@cbnu.ac.kr

C 2013 The Korean Society of Sericultural Sciences 
and Pythium myriotylum have been reported by numerous studies (Goettel et al., 2008; Lee et al., 2005). Additionally, these metabolites exhibit a wide variety of insecticidal, antibacterial, antifungal, anticancer, antioxidant, and antiviral activities, and they have been suggested as potential candidates for the development of new bioactive agents (Isaka et al., 2005; Pedras et al., 2002; Wang and Xu, 2012).

These findings confirm the potential of entomopathogenic fungi as sources of lead compounds in pharmaceutical interests. Therefore, in this study, we report our results by assessing the ability of entomopathogenic fungi isolated in Korea (Shin et al., 2013) to produce antibacterial metabolites against Escherichia coli and their biochemical characteristics.

\section{Materials and Methods}

\section{Entomopathogenic fungal metabolites}

Entomopathogenic fungi, which exhibit virulence against the great wax moth (Galleria mellonella L. [Lepidoptera: Pyralidae]), were used in this study (Table 1) (Shin et al., 2013). For initial screening of antibacterial compounds, $1 \mathrm{ml}$ of sabouraud dextrose broth containing a yeast extract medium (SDYB; 10 $\mathrm{g}$ Bacto Peptone, $40 \mathrm{~g}$ Dextrose, and $10 \mathrm{~g}$ yeast extract in 1000 $\mathrm{ml}$ distilled water; $\mathrm{pH} \mathrm{6.0)}$ ) was placed in a 2-ml microcentrifuge tube. The samples were then inoculated with a one-agar block (6 mm) of fungi collected from 2-week-old potato dextrose agar (PDA; Difco, USA). Samples were cultured at $25^{\circ} \mathrm{C}$ in the dark and were shaken at $150 \mathrm{rpm}$ for 10 days, after which the samples were centrifuged at 13,000 rpm for $10 \mathrm{~min}$. The aqueous upper layer was transferred into a Plasmid DNA collection kit column (COSMO GENETECH) to filter spores and mycelia.

For quantitative assay, all fungal conidia were obtained by scraping a 2-week-old PDA plate and suspended in a $0.05 \%$ Tween- 80 solution. The conidial suspension was vigorously agitated and filtered through cotton to remove mycelial debris. After counting the number of conidia, $50 \mu 1$ of the conidial suspension $\left(2 \times 10^{6}\right.$ conidia/ml $)$ was inoculated with $20 \mathrm{ml}$ of SDYB medium in a 100-ml Erlenmeyer flask and cultured using the abovementioned method. After 10 days, the samples were centrifuged at 13,000 rpm for $20 \mathrm{~min}$. The pellet was removed and the supernatant was filtered using a $0.45 \mu \mathrm{m}$ membrane
Table 1. Entomopathogenic fungal isolates used in this study

\begin{tabular}{|cc|}
\hline Species & Isolate \\
\hline Beauveria bassiana & \\
\hline & CN5R1W1 \\
\hline CB12M1W1 \\
\hline JN1T1W1 \\
\hline Isaria farinosa & \\
\hline & KB20M2W1 \\
\hline Ketarhizium anisopliae var. anisopliae & \\
\hline & JB5G2W1 1 \\
\hline & CN6S1W1 \\
\hline & CN2T1W1 \\
\hline Kyrothecium sp. & KW5M4W1 \\
\hline & JB11S2W2 \\
\hline
\end{tabular}

filter (ADVACTEC No. 2) to separate the crude extract from the mycelium and spore mass. All fungal cell-free culture filtrates were stored at $-70^{\circ} \mathrm{C}$ until antibacterial activity could be detected.

\section{Bacterial strain}

For the preparation of bacteria, E. coli XL1Blue was cultured using a LB media (10 $\mathrm{g}$ tryptone, $5 \mathrm{~g}$ yeast extract, and $5 \mathrm{~g}$ sodium chloride in $1000 \mathrm{ml}$ distilled water; $\mathrm{pH} 7.0$ ). One $\mathrm{ml}$ of $E$. coli culture suspension incubated overnight was inoculated into $100 \mathrm{ml}$ of LB media and grown to the mid-exponential phase $($ O.D. $.650 \mathrm{~nm}=\sim 0.5)$.

\section{Antibacterial activity assay}

Antibacterial activity against E. coli was determined using a broth dilution method (du Toit and Rautenbach, 2000). The bacterial cells of the mid-exponential phase were diluted with LB media to $1 \times 10^{3} \mathrm{CFU} / \mathrm{ml}$ (for the screening assay) and $5 \times$ $10^{5} \mathrm{CFU} / \mathrm{ml}$ (for the quantitative assay), respectively. For the screening assay, $100 \mu \mathrm{l}$ of bacterial suspensions were placed in 96 wells with $100 \mu \mathrm{l}$ of the fungal culture filtrate and incubated at $37^{\circ} \mathrm{C}$ for $16 \mathrm{~h}$. To determine bacterial growth inhibition, the absorbance of the each well was measured at $650 \mathrm{~nm}$ by using a 
microplate reader (Molecular Devices, UK). A bacterial culture well grown in SDYB or LB medium without the fungal culture filtrate was used as the positive control well.

For the quantitative assay, $100 \mu \mathrm{l}$ of bacterial suspensions were placed in 96 wells and then mixed with $100 \mu \mathrm{l}$ of the fungal culture filtrate at different concentrations (i.e., $1 \%$, $10 \%, 20 \%, 40 \%, 60 \%, 80 \%$, and $100 \%$ ). The fungal culture filtrate was diluted with SDYB media. For the control, bacterial suspensions were cultured in SDYB media with different concentrations of PBS in place of the fungal culture filtrate. All experiments were performed in triplicate.

\section{MTT assay}

Bacterial cell viability was assessed by MTT [3-(4,5dimethylthiazol-2-yl)-2,5-diphenyltetrazolium bromide] assay based on the reduction of MTT to formazan dye by active mitochondria. Briefly, $20 \mu \mathrm{l}$ of the MTT solution $(5 \mathrm{mg} / \mathrm{ml}$ in PBS) was added to each well and incubated for $4 \mathrm{~h}$. Then, the MTT-spiked media was carefully removed by centrifugation at 13,000 rpm for $10 \mathrm{~min}$, and formazan formed in the cells was dissolved in $200 \mu$ l of dimethyl sulfoxide. Absorbance at $540 \mathrm{~nm}$ was read using a micro plate reader (Molecular Devices, UK).

\section{Stability of antibacterial activity of culture filtrate}

For determining the heat stability, the culture filtrate was treated at various temperatures $\left(50^{\circ} \mathrm{C}, 80^{\circ} \mathrm{C}, 100^{\circ} \mathrm{C}\right.$, and $\left.121^{\circ} \mathrm{C}\right)$ for $15 \mathrm{~min}$. After thermal shock, the culture filtrate was quickly cooled to $25^{\circ} \mathrm{C}$, and its antibacterial activity was evaluated.

To test its stability in the presence of a protease, the culture filtrate was treated with proteinase K (Sigma, USA) at a final concentration of $1 \mathrm{mg} / \mathrm{ml}$ under the condition of $37^{\circ} \mathrm{C}$ for $2 \mathrm{~h}$. Then, the culture filtrate was autoclaved at $121^{\circ} \mathrm{C}$ for $15 \mathrm{~min}$ to inactivate the enzymes before the antibacterial activity assay was conducted.

\section{Results}

\section{Screening of fungi showing antibacterial activity}

Primary screening for the antibacterial activity of entomo-

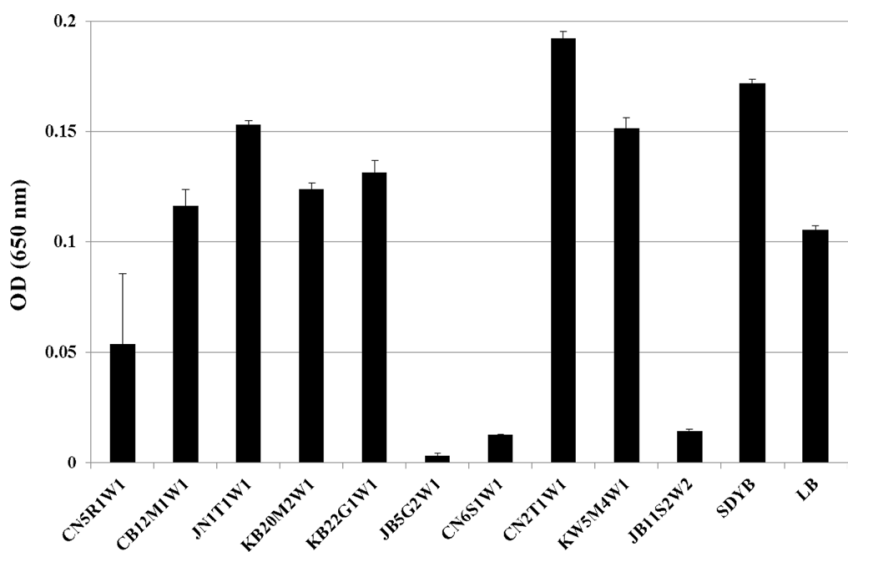

Fig. 1. Growth of E. coli in LB media with culture filtrates of entomopathogenic fungi for $16 \mathrm{~h}$. Vertical bars correspond to standard error.

pathogenic fungal isolates was carried out using a broth dilution assay. Among the 10 isolates tested, the culture filtrate of 4 isolates (i.e., B. bassiana CN5R1W1, M. anisopliae var. anisopliae JB5G2W1, CN6S1W1, and Myrothecium sp. JB11S2W2) exhibited high antibacterial activity (Fig. 1). Bacterial growth was reduced to approximately 2-20 and 3-30 times that in the LB and SDYB media, respectively. These fungal isolates were used for further studies to clarify the production of antibacterial compounds.

\section{Quantitative assay of antibacterial activity}

Fungi were selected for scale-up culture with the same concentration of conidia and they were them subjected to a quantitative assay. The culture filtrate of $M$. anisopliae var. anisopliae JB5G2W1 showed the highest antibacterial activity, followed by that of $M$. anisopliae var. anisopliae $\mathrm{CN} 6 \mathrm{~S} 1 \mathrm{~W} 1$ and B. bassiana CN5R1W1 (Fig. 2). Antibacterial activity increased with increasing concentrations of the culture filtrate. However, the culture filtrate of Myrothecium sp. JB11S2W2, which showed a high activity rate at the initial screening stage, did not show any significant antibacterial activity in the quantitative assay.

\section{Cell viability assay}

Surviving bacterial cell numbers in each well treated with $100 \%$ of the culture filtrate were determined indirectly by MTT 


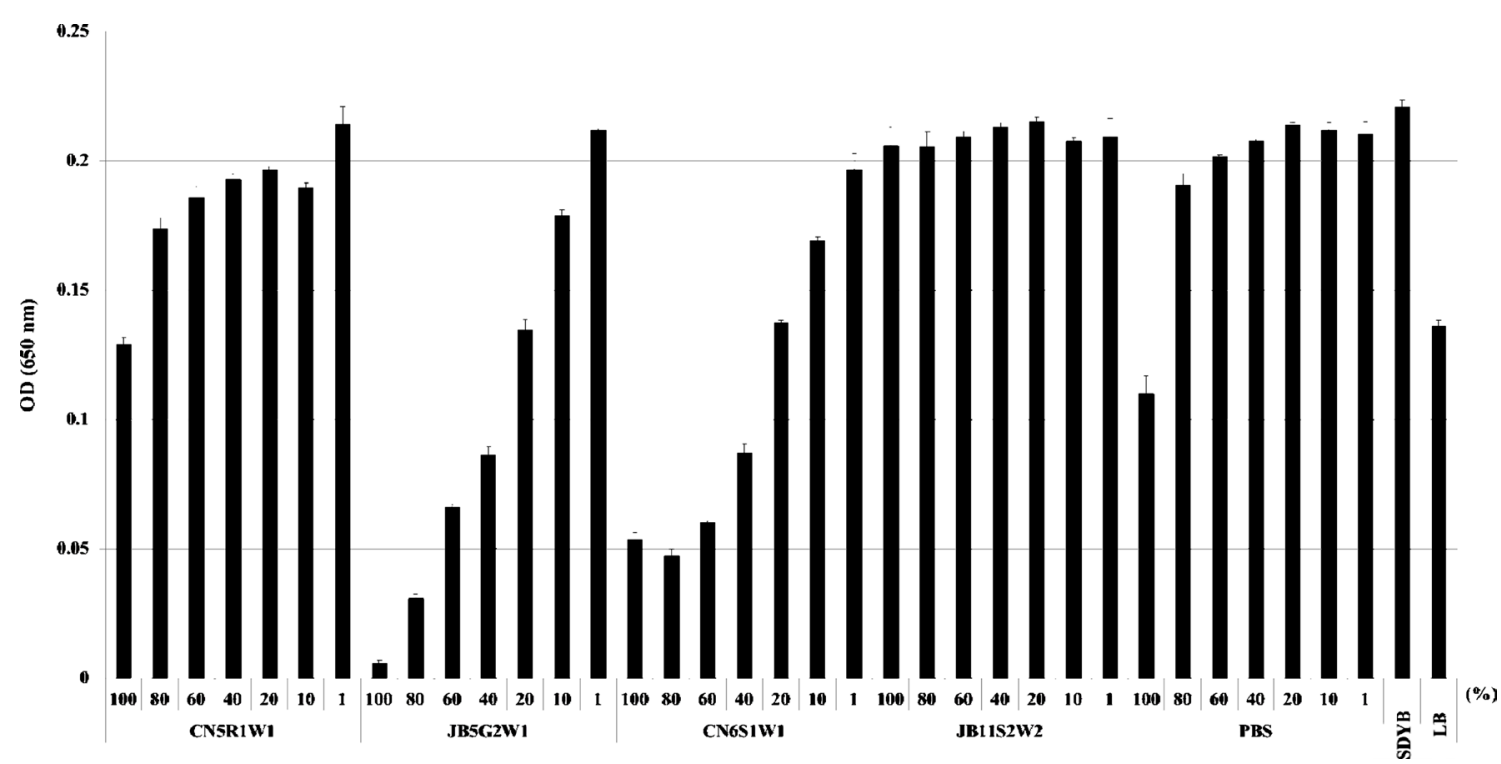

Fig. 2. Antibacterial activity of culture filtrates of entomopathogenic fungi at different concentrations (1\%, 10\%, 20\%, 40\%, 60\%, $80 \%$, and $100 \%$ ) against $E$. coli for $16 \mathrm{~h}$. Vertical bars correspond to standard error.

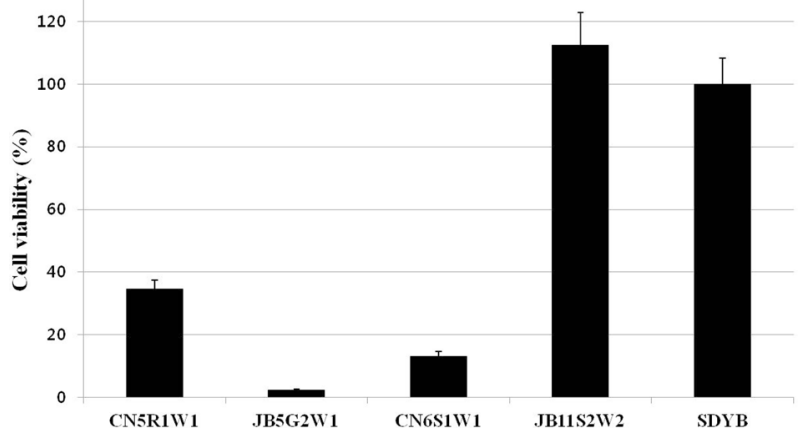

Fig. 3. Bacterial cell viability for fungal culture filtrates. Cell viability was assessed by MTT assay. Vertical bars correspond to standard error.

assay. As a result, for all fungal culture filtrates, no differences were detected between the O.D. (Fig. 2) and cell viability values (Fig. 3) obtained by both assays.

\section{Stability of antibacterial activity}

The stability of culture filtrates to heat and protease treatments were evaluated for antibacterial activity. Heat treatment did not influence the antibacterial activity of the culture filtrate for all tested isolates (Table 2). Furthermore, the culture filtrate retained its antibacterial activity even after treatment at $121^{\circ} \mathrm{C}$ for $15 \mathrm{~min}$. The hydrolytic enzyme, proteinase $\mathrm{K}$, also had no effect on the antibacterial activity of all culture filtrates (Table 2).

\section{Discussion}

Beauveria bassiana and $M$. anisopliae are the most commonly isolated species in the world (Vega et al., 2012), thus making them the most widely known among entomopathogenic fungi and fostering their use as biocontrol agents against a variety of pests in various countries (de Faria and Wraight, 2007). These 2 species are also the most commonly used in the study of fungal metabolites (Pedras et al., 2002; Wang and $\mathrm{Xu}, 2012$ ). In the present study, B. bassiana and $M$. anisopliae (including Isaria farinosa and Myrothecium sp.) culture filtrates were tested for their antibacterial activity against $E$. coli. Initial screening results showed that 4 of 10 isolates exhibited high antibacterial activity against bacterial cells $\left(1 \times 10^{2} \mathrm{CFU}\right)$. These results corresponded with previous reports that entomopathogenic fungi can exhibit antibacterial activity (Isaka et al., 2005; Pedras et al., 2002; Wang and Xu, 2012). However, Myrothecium sp. JB11S2W2 showing high antibacterial activity in the initial screening assay did not show any antibacterial activity against a high concentration of bacterial cells (i.e., $5 \times 10^{4} \mathrm{CFU}$; Fig. 2). This result may be explained by 2 lines of reasoning. First, the data obtained may be because of differences in the antibacterial compound yield between initial screening and quantitative assays. In the initial screening assay, the concentration of conidia for inoculation 
Table 2. Effect of temperature and enzymatic shock on the antibacterial activity of culture filtrates of entomopathogenic fungi. Data represent mean values of 3 replicates with standard error

\begin{tabular}{|c|c|c|}
\hline Isolates & Treatment & OD (650 nm) \\
\hline \multicolumn{3}{|c|}{ CN5R1W1 } \\
\hline & $50^{\circ} \mathrm{C}, 15 \mathrm{~min}$ & $0.12 \pm 0.000$ \\
\hline & $80^{\circ} \mathrm{C}, 15 \mathrm{~min}$ & $0.075 \pm 0.000$ \\
\hline & $100^{\circ} \mathrm{C}, 15 \mathrm{~min}$ & $0.073 \pm 0.002$ \\
\hline & $121^{\circ} \mathrm{C}, 15 \mathrm{~min}$ & $0.085 \pm 0.004$ \\
\hline & Proteinase K & $0.099 \pm 0.000$ \\
\hline & Untreated & $0.129 \pm 0.002$ \\
\hline \multicolumn{3}{|c|}{ JB5G2W1 } \\
\hline & $50^{\circ} \mathrm{C}, 15 \mathrm{~min}$ & $0.004 \pm 0.000$ \\
\hline & $80^{\circ} \mathrm{C}, 15 \mathrm{~min}$ & $0.001 \pm 0.000$ \\
\hline & $100^{\circ} \mathrm{C}, 15 \mathrm{~min}$ & $0.001 \pm 0.000$ \\
\hline & $121^{\circ} \mathrm{C}, 15 \mathrm{~min}$ & $0.000 \pm 0.000$ \\
\hline & Proteinase K & $0.000 \pm 0.000$ \\
\hline & Untreated & $0.006 \pm 0.000$ \\
\hline \multicolumn{3}{|c|}{ CN6S1W1 } \\
\hline & $50^{\circ} \mathrm{C}, 15 \mathrm{~min}$ & $0.057 \pm 0.001$ \\
\hline & $80^{\circ} \mathrm{C}, 15 \mathrm{~min}$ & $0.023 \pm 0.005$ \\
\hline & $100^{\circ} \mathrm{C}, 15 \mathrm{~min}$ & $0.038 \pm 0.001$ \\
\hline & $121^{\circ} \mathrm{C}, 15 \mathrm{~min}$ & $0.041 \pm 0.001$ \\
\hline & Proteinase K & $0.047 \pm 0.001$ \\
\hline & Untreated & $0.053 \pm 0.002$ \\
\hline
\end{tabular}

was not determined, but it was determined and inoculated in the quantitative assay. The conidial concentration for inoculation may have been insufficient to produce a substantial yield of antibacterial compounds from Myrothecium sp. JB11S2W2. Second, it may be related to differences in the tested bacterial concentrations. Although antibacterial compound(s) from Myrothecium sp. JB11S2W2 was sufficient to reduce the growth of low concentrations of bacteria (i.e., 1 $\times 10^{2} \mathrm{CFU}$ ), it may not have affected all bacterial cells at high concentrations (i.e., $5 \times 10^{4} \mathrm{CFU}$ ). These reasons should be clarified through further studies.

To determine whether the antibacterial activity of the fungal culture filtrate showed cytotoxic or cytostatic effects against $E$. coli, an MTT assay was performed. The results showed that the antibacterial compound did not completely suppress bacterial growth (Fig. 3). The data presented could not confirm the reason for the antibacterial activity of the fungal culture filtrate. Further studies need to be performed to elucidate this finding.

Antibacterial compound(s) produced from selected fungal isolates remained stable in response to heat and proteolytic enzyme treatments (Table 2). These results suggest that the antibacterial compound(s) is not a protein. Heat-stable antimicrobial compounds are not commonly produced. Some Class II bacteriocins have been reported to be heat stable (Bharti et al., 2012; Drider et al., 2006). Therefore, the antibacterial compound produced from our fungal isolates may have useful applications in various fields of study.

Fungi produce a wide range of compounds with biological activities against other organisms; most of these are products of secondary metabolites (Vey et al., 2001). In recent years, beauvericin and destruxins have become well-known secondary metabolites produced from many entomopathogenic fungi such as $B$. bassiana and $M$. anisopliae. These metabolites exhibit a wide variety of insecticidal, antibacterial, antifungal, anticancer, and antiviral activities (Pedras et al., 2002; Wang and $\mathrm{Xu}, 2012$ ). These findings confirm the potential of entomopathogenic fungi as a source for lead structures of pharmaceutical interest. In our study, the antibacterial activity against $E$. coli was tested and demonstrated by using only entomopathogenic fungi that showed insecticidal activity against the great wax moth. Therefore, other biological activities should also be evaluated, and further investigation into the antibacterial activity compound(s) from our fungal isolates is also required. These studies will increase the usefulness of entomopathogenic fungi as biological control agents in addition to other biological applications.

\section{Acknowledgements}

This work was supported by the research grant of the Chungbuk National University in 2011 and the Basic Science Research Program through the National Research Foundation of Korea (NRF) funded by the Ministry of Education, Science and Technology (No. 2011-0013004). 


\section{References}

Bharti P, Anand V, Chander J, Singh IP, Singh TV, Tewari R (2012) Heat stable antimicrobial activity of Burkholderia gladioli OR1 against clinical drug resistant isolates. Indian J Med Res 135(5), 666-671.

de Faria MR, Wraight SP (2007) Mycoinsecticides and mycoacaricides: a comprehensive list with worldwide coverage and international classification of formulation types. Biol Control 43(3), 237-256.

Drider D, Fimland G, Héchard Y, McMullen LM, Prévost H (2006) The continuing story of class IIa bacteriocins. Microbiol Mol Biol Rev 70(2), 564-582.

du Toit EA, Rautenbach M (2000) A sensitive standardised micro-gel well diffusion assay for the determination of antimicrobial activity. $\mathrm{J}$ Microbiol Methods 42(2), 159-165.

Goettel MS, Koike M, Kim JJ, Aiuchi D, Shinya R, Brodeur J (2008) Potential of Lecanicillium spp. for management of insects, nematodes and plant diseases. J Invertebr Pathol 98(3), 256-261.

Isaka M, Kittakoop P, Kirtikara K, Hywel-Jones NL, Thebtaranonth Y (2005) Bioactive substances from insect pathogenic fungi. Acc Chem Res 38(10), 813-823.

Lee SY, Nakajima I, Ihara F, Kinoshita H, Nihira T (2005) Cultivation of entomopathogenic fungi for the search of antibacterial compounds. Mycopathologia 160(4), 321-325.

Molnár I, Gibson DM, Krasnoff SB (2010) Secondary metabolites from entomopathogenic Hypocrealean fungi. Nat Prod Rep 27(9), 1241-1275.

Pedras MS, Irina Zaharia L, Ward DE (2002) The destruxins: synthesis, biosynthesis, biotransformation, and biological activity. Phytochemistry 59(6), 579-596.

Shin TY, Lee WW, Ko SH, Choi JB, Bae SM, Choi JY, Lee KS, Je YH, Jin BR, Woo SD (2013) Distribution and characterization of entomopathogenic fungi from Korean soils. Biocontrol Sci Techn 23(3), 288-304.

Vega FE, Meyling NV, Luangsa-ard JJ, Blackwell M (2012) Fungal Entomopathogens; In Insect Pathology: Second Edition. Vega FE, Kaya HK (eds), pp. 171-220, Academic Press Inc, New York.

Vey A, Hoagland RE, Butt TM (2001) Toxic metabolites of fungal biocontrol agents; In Fungi as Biocontrol Agents. Butt TM, Jackson C, Magan N (eds), pp. 311-346, Wallingford, CABI Publishing.

Wang Q, Xu L (2012) Beauvericin, a bioactive compound produced by fungi: a short review. Molecules 17(3), 2367-2377. 